УДК 316

$10.17213 / 2075-2067-2020-4-105-114$

\title{
ВНЕШНЯЯ МОЛОДЕЖНАЯ ПОЛИТИКА \\ КАК ИНСТРУМЕНТ ВОВЛЕЧЕНИЯ МОЛОДЫХ СООТЕЧЕСТВЕННИКОВ В ПРОЦЕСС ГРАЖДАНСКОЙ СОЦИАЛИЗАЦИИ
}

(C) 2020 г. . К. Ростовская, В. А. Гневашева, Г. Н. Очирова

\author{
Институт демографических исследований \\ Федерального научно-исследовательского социологического центра РАН, \\ 2. Москва, Россия
}

В соответствии с современным теоретическим осмыслением молодежи как значимой социальной когорты общества молодежную политику следует понимать, как иеленаправленную организацию действий определенных структур (институтов) общества, направленную на утверждение у молодежи определенных ценностно-нормативных систем. Молодежная политика может быть определена как инструмент процесса социализации молодежи. Внешняя молодежная политика, направленная на вовлечение молодых соотечественников, проживающих за рубежом, в прочесс гражданской сочиализации, в свою очередь опирается на инструмент политической социализации. Важность данного вида социализачии для утверждения норм и иеенностей государственности предопределена современными условиями глобализации всех сфер жизнедеятельности общества.

Ключевые слова: внешняя государственная молодежная политика; политическая соииализация; гражданская сочиализация; молодежь; «молодые соотечественники».

\section{EXTERNAL YOUTH POLICY AS A TOOL FOR YOUNG COMPATRIOTS INVOLVING IN THE PROCESS OF CIVIL SOCIALIZATION}

\section{(C) 2020 T. K. Rostovskaya, V. A. Gnevasheva, G. N. Ochirova}

\section{Institute of Demographic Research of the Federal Research Sociological Center of the Russian Academy of Sciences, Moscow, Russia}

In accordance with the modern theoretical understanding of youth as a significant social cohort of society, youth policy should be understood as a purposeful organization of actions of certain structures (institutions) of society, aimed at affirming certain value-normative systems among young people. Youth policy can be defined as a tool for the process of youth socialization. External

1 Статья подготовлена при финансовой поддержке РФФИ в рамках научного проекта №20-011-31321 «Российская государственная молодежная политика как инструмент работы с молодыми соотечественниками за рубежом: формирование, реализация, совершенствование». 
youth policy aimed at involving «young compatriots» in the process of civil socialization, in turn, is based on the tool of political socialization. The importance of this type of socialization for the establishment of the norms and values of statehood is predetermined by the modern conditions of globalization of all spheres of society.

Key words: foreign state youth policy; political socialization; civil socialization; youth; «young compatriots».

В постсоветской России практика регулирования вопросов молодежной политики представляет механизм конкретных решений для формирования условий и стимулов решения молодежью собственных проблем.

Изначально исторически правовые меры по молодежной проблематике предпринимались лишь в отдельных сферах регулирования общественных отношений, как например, в соответствии с регулятором труда молодых рабочий в Пруссии (в 1839 г.) в области труда и занятости молодежи.

В Европейских странах постепенно формировались мероприятия по защите бедных среди молодежи, исходя из гуманитарных соображений, а также меры превентивной политики регулирования социальных волнений и провокаций конфликтов в обществе.

Подобные идеи были зафиксированы и в процессе формирования ювенальной юстиции в царской России и впоследствии.

В стратегическом замысле молодежная политика становится значимой с целью урегулирования кризиса взаимоотношения поколений и восстановления эффективных форм межпоколенческих взаимодействий для устойчивого развития общества как целого.

Как отмечают исследователи, целенаправленность молодежной политики предопределена необходимостью регулирования межпоколенческих отношений, обеспечения преемственности и через формирование подобных процессов - развития общества [7].

Следует отметить, что формирование и развитие государственной молодежной политики определено концепцией «хорошего общества» [25], которое во многом зависит от того, что признается проблемами молодежи в данном обществе. В современном российском обществе актуальными вызовами для государственной социальной политики в целом и молодежной политики в частности являются проблемы человеческого капитала, особенно в части его снижения для молодежной страты как в количественном, так и в качественном выражении, что может быть отчасти решено за счет мер привлечения и сохранения на территории России талантливой и инициативной молодежи, в первую очередь из числа молодых соотечественников. В соответствии с Основами государственной молодежной политики Российской Федерации на период до 2025 года «молодежь» определяется как социально-демографическая группа, «выделяемая на основе возрастных особенностей, социального положения и характеризующаяся специфическими интересами и ценностями. Эта группа включает лиц в возрасте от 14 до 30 лет, а в некоторых случаях, определенных нормативными правовыми актами Российской Федерации и субъектов Российской Федерации, — до 35 и более лет, имеющих постоянное место жительства в Российской Федерации или проживающих за рубежом (граждане Российской Федерации и соотечественники)» [15].

В настоящем исследовании к молодым соотечественникам будем относить лиц в возрасте до 30 лет, а в некоторых случаях, определенных нормативными правовыми актами Российской Федерации и субъектов Российской Федерации, - до 35 и более лет [15], «... проживающих за пределами территории Российской Федерации и относящихся, как правило, к народам, исторически проживающим на территории Российской Федерации, а также сделавших свободный выбор в пользу духовной, культурной и правовой связи с Российской Федерацией лиц, чьи родственники по прямой восходящей линии ранее проживали на территории Российской Федерации» [24].

Следует согласиться с авторской позицией о бесценной роли молодых соотечественников, которые являются «...наследниками ве- 
ликой русской (российской) культуры, носителями и выразителями её огромного социокультурного потенциала (традиционных смыслов и ценностей в организации бытийного мира; духовно-нравственных воззрений на роль человека в мире; миссионерских идей о внесении гармонии в окружающий мир; народной педагогики; литературы и искусства, др.)» [5].

В этой связи в контексте новых социально-экономических и геополитических условий актуальным является не только исследование тенденций особенностей жизнедеятельности молодых соотечественников, а также усиление государственной молодежной политики России в части социально-экономической поддержки русскоговорящего населения за рубежом.

Это обусловлено рядом причин.

Во-первых, тенденции и социально-демографическая структура эмиграции подвержены постоянным изменениям в зависимости от социально-экономических и геополитических факторов. Экономические кризисы и политические санкции существенно поменяли факторы, тенденции и структуру эмиграции из России в последние годы.

Во-вторых, геополитическая ситуация вокруг Российской Федерации и положение мигрантов из России существенно поменялись после введения санкций со стороны западных стран, получила широкое распространение русофобия как на государственном, так и на бытовом уровнях. Русские сообщества и иммигранты из России за границей стали «передовыми» форпостами, на которые проецируется отношение правительств, социальных групп, отдельных людей к Российской Федерации. Участились случаи обвинения в противоправной деятельности и задержания российских граждан на территории других государств.

В-третьих, государственная политика Российской Федерации существенно усилилась в направлении поддержки соотечественников за рубежом, особенно в культурном, юридическом, политическом, духовном аспектах. IV Всемирный конгресс соотечественников, проживающих за рубежом, который состоялся в 2018 году в Москве, собрал более 400 делегатов из 98 стран мира.

Российское государство оказывает содействие Фонду поддержки и защиты прав соотечественников, проживающих за рубежом, благодаря которому в 30 странах создано 26 центров правовой помощи, где квалифицированную юридическую помощь получили свыше 70 тысяч человек, 200 проектов получили грантовую поддержку, проведено более 50 мероприятий, включая курсы по подготовке молодых правозащитников.

Продолжается реализация Программы добровольного переселения соотечественников в Россию (за 12 лет ее реализации в 66 субъектов Федерации переехало около 800 тысяч человек), но при этом остаются недостаточно проработанными социальноэкономические аспекты государственной политики Российской Федерации.

В-четвертых, существенно диверсифицируются формы консолидации соотечественников (появляются не только культурные клубы, но и экономические организации, компании, политические группы и пр.) и во взаимодействие с Россией вовлекаются новые социальные группы населения (например, молодежь).

В настоящее время объединения российских соотечественников действуют более чем в 100 государствах мира. Их роль значительна в изучении русского языка, популяризации российской культуры, распространении православия, налаживании экономических отношений с Россией. Требует поддержки социально-экономическая деятельность мигрантов из России и соотечественников за рубежом как медиаторов между Россией и принимающими странами. В современной российской науке вопросы эмиграции из России и формирования русскоговорящих сообществ за рубежом, в особенности в постсоветский период, изучаются в меньшей степени, нежели вопросы иммиграции в Россию.

В результате подобные процессы находят отражение в миграционной политике страны, которая имеет явный «перекос» в сторону регулирования иммиграции и практически «не замечает» эмиграцию, хотя в результате эмиграции страну покидают квалифицированные трудовые ресурсы, высококвалифицированные специалисты, молодежь и люди репродуктивного возраста.

Среди исследований российских и зарубежных авторов последних лет по вопросам эмиграции из стран бывшего СССР и России, 
а также общих вопросов эмиграции можно выделить несколько направлений.

Во-первых, статистико-географические исследования российской эмиграции (например, исследования Я. Трухина [22], М.Б. Денисенко [4], С. В. Рязанцева и М.Ф. Ткаченко [20], Р. Е. Билсбрроу, Г. Хьюго, А. С. Обераи, Х. Злотника [2], П. Колсто [1] и др.).

Во-вторых, историческое направление исследований эмиграции (П.М. Полян [16], Ж. А. Зайончковская и Г.С. Витковская [17], А. Тинги [23] и др.).

В-третьих, эмиграция из России в ряде исследований рассматривается как процесс «утечки умов» (в частности, в работах таких исследователей, как В. Покровский [14], А. А. Казанцев, К. П. Боришполец [8] и др.).

Молодежная когорта характеризуется специфичностью действия социально-экономического механизма в процессе становления ценностно-нормативной системы и ее трансформации [6, 10, 11, 12].

В авторских исследованиях (В.А. Гневашева, Т.К. Ростовская ${ }^{2}$ ) ценности молодежи определялись на основании косвенных вопросов, учитывая тот факт, что молодежь находится в активной фазе вторичной социализации и именно на этом этапе процесс социализации следует рассматривать как двусторонний. С одной стороны, важным социализирующим агентом выступает само общество, которое предопределяет для молодого человека некоторые ценностные тренды, ограничивая возможности поведения определёнными ценностными нормами. С другой стороны, индивид, личностно воспринимая внешний посыл общества, формирует с учетом внутренней личностной основы собственные ценностные преференции в своем поведении и собственные ценностные ожидания в отношении поведения других. Как следствие - создается условная социальная сеть разнонаправленных воздействий в отношении личности.

Получается, что ценностные ориентации молодых людей с одной стороны отражают общественные предпочтения, с другой имеют личностное преломление в зависи- мости от индивидуальных особенностей принятия внешних ценностных посылов.

В то же время ценностные ориентации во многом сохраняются в поколениях и имеют особенности межпоколенческого наследия, как личностного, так и посредством иных форм передачи информации [10, 11, 12].

По итогам исследований интересно отметить особенности гражданской идентификации молодежи (рис. 1).

Результаты исследования четко отражают доминантную позицию, социальный маркер в отношении определения гражданской идентификации, а именно: факт юридической связи индивида с государством, гражданскую принадлежность. Также важным отличительным фактором, во многом определяющим политическую идентификацию является образ социально-политического мышления - менталитет. Однако, в силу наличия множественности выбора в данном вопросе подобная ситуация свидетельствует с одной стороны об отсутствии четкого понимания фактора гражданской идентификации в контексте «индивид — общество»; с другой о значимости гражданской принадлежности как фактора, определяющего социально-экономические и политические ценности включенных в это сообщество людей вне зависимости от территории проживания.

В этой связи условия современного территориального распределения населения позволяют говорить о значимости гражданственной или политической идентификации как системообразующего фактора, включающего ценностный, социальный, экономический, политический аспекты.

Американский политолог Г. Алмонд [21], изучавший вопросы трансформации политической системы России, отметил кардинальное изменение роли социальных институтов в части формирования процессов политической социализации.

Условия смены политических ценностей, норм и приоритетов проявляются в кризисе политической социализации, и ключевыми институтами, в том числе и политической

2 В 2006-2018 гг. общероссийский мониторинг «Российский студент: социальный облик» (В. А. Гневашева — основной исполнитель и далее руководитель ряда этапов мониторинга с 2011-2018 гг.); 2018 год — Международное социологическое исследование на тему «Ценностные ориентации молодежи России и Казахстана», рук. Т.К. Ростовская. 
социализации, становятся: семья, система образования, СМИ, общественные и религиозные организации. При этом наиболее действенным остается семья как малая социальная группа первичной социализации.

Система образования как институт политической социализации становится значимой через механизмы устойчивой ретрансляции знаний о политическом поле, сопряженных с ним процессов и оценок, формируя в том числе эмоциональную привязанность к символам государственной власти. В этой связи считается, что образованный человек более политически информирован и в этой связи в большей мере склонен к участию в политической жизни общества.

Определяя социальную жизнь молодежи как некоторую систему социальных полей, можно отметить, что к примеру, Ф. Гиддингс включает в систему социального пространства «оценивание» (Appreciation), «использование» (Utilization), «характеризацию» (Characterization) и «социализацию» (Socialization).

Специфика социализации в этой связи определяется способностью приспособиться друг к другу. Ценностно ориентированный вектор общественного становления важно рассматривать именно в этом направлении, формируя ряд мероприятий и регуляторов на каждом предварительном этапе.

Социализация, по И. Кону, представляет собой «процесс усвоения человеческим индивидом определенной системы знаний, норм и ценностей, позволяющих ему функционировать в качестве полноправного члена общества. Социализация включает как социально контролируемые процессы целенаправленного воздействия на личность (воспитание), так и стихийные, спонтанные процессы, влияющие на ее формирование» [9].

Следует согласиться с российскими учеными Т.К. Ростовской, С.Н. Фоминой, которые в качестве основного критерия эффективности проводимой государственной молодежной политики отмечают «...увеличение численности молодых людей, мотивированных на позитивные действия, разделяющих общечеловеческие и национальные духовные ценности, обладающих хорошим физическим здоровьем, занимающихся физической культурой и спортом, не имеющих вредных привычек, работающих над своим личностным и профессиональным развитием, любящих свое Отечество и готовых защищать его интересы, прилагающих усилия для ди-

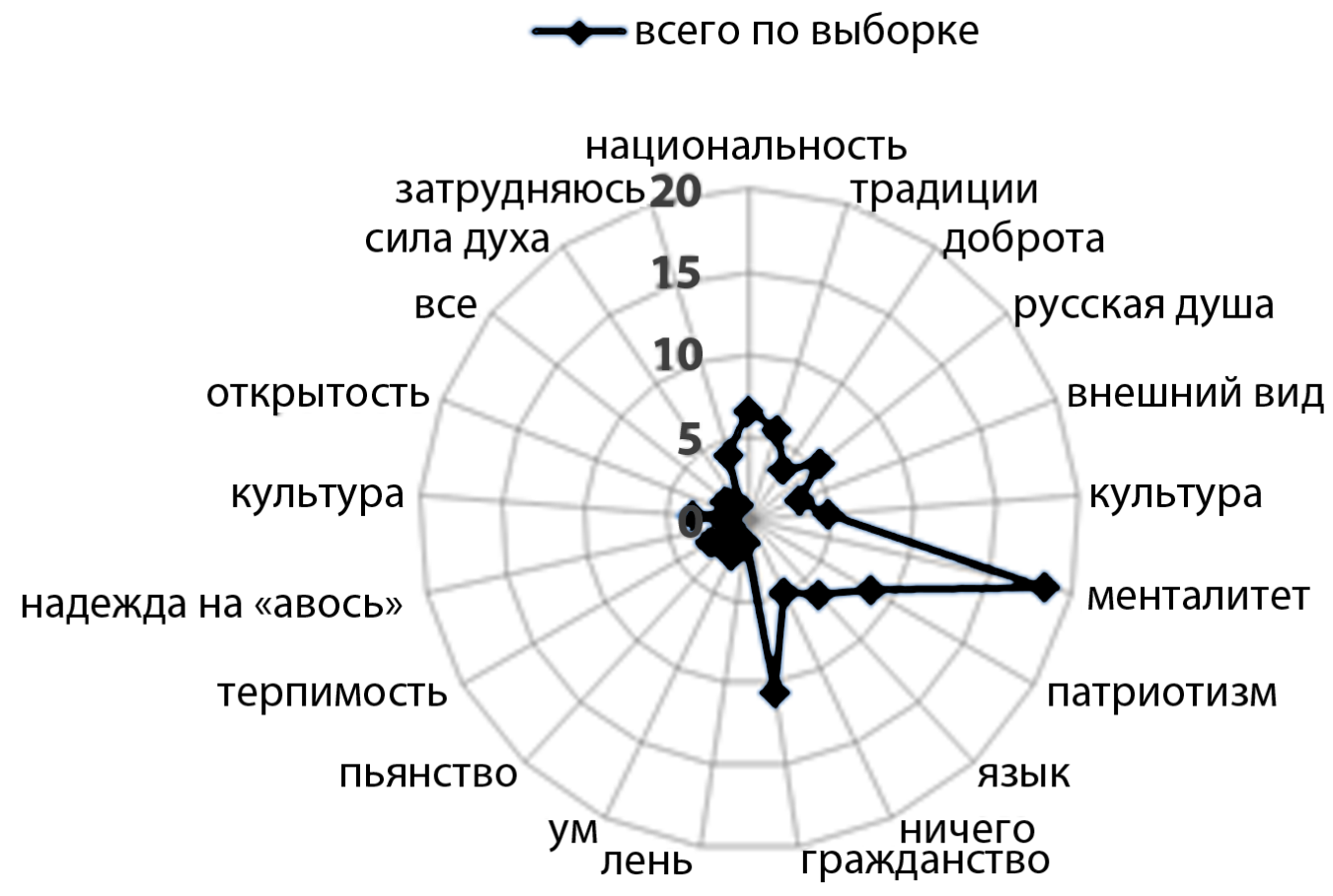

Рис. 1. Распределение ответов респондентов на вопрос «Что отличает граждан России от граждан других стран?» (в \%) 
намичного развития сильной и независимой России» [18].

В этом смысловом контексте проблемы социализации молодых соотечественников и формирование их социокультурной идентичности становятся основными факторами реализации внешней государственной молодежной политикой.

На основе авторских исследований, a также предложенных методологических и теоретических оценок, внешняя государственная молодежная политика может быть определена как направление деятельности Российской Федерации в отношении «молодых соотечественников», сохранивших гражданскую идентичность с Российской Федерацией, представляющее собой систему мер нормативно-правового, финансово-экономического, организационно-управленческого, информационно-аналитического, кадрового и научного характера, реализуемых на основе взаимодействия с национальными и международными институтами гражданского общества, направленных на усиление политической и гражданской идентификации «молодых соотечественников», с целью расширения возможностей для эффективной самореализации «молодых соотечественников» и повышения уровня их потенциала для достижения устойчивого развития глобальной конкурентоспособности государства, обеспечения его национальной безопасности, а также упрочения политико-гражданских позиций ее граждан в глобальном сообществе.

Выводы. Направленность государственной молодежной политики сегодня должна быть четко ориентирована не только на внутриобщественные интересы, но и на формирование некоторого глобального пространства ценностно-нормативного регулирования членов молодежной когорты, имеющих гражданскую и (или) политическую идентичность с Россией.

Формирование нового терминологического понятия, позволяющего детерминировать более объемный тезаурус молодежи России по гражданско-патриотическим критериям, может быть представлено именно определенным в рамках данного исследования понятием внешней государственной молодежной политики.
Политическая и гражданская идентификация как инструменты внешней молодежной политики позволяют оценить степень включенности членов молодежной группы в систему политических и гражданских корреляций и сформировать механизмы ценностно-нормативного регулирования устойчивости молодежных социальных взаимодействий в рамках расширенного социального пространства в отношении «молодых соотечественников».

\section{Литература}

1. Kolsto $P$. The new Russian diaspora - An identity of its own? Possible identity trajectories for Russians in the former Soviet republic// Ethnic and Racial Studies. - 1996. — №19 (3). Pp. 609-639.

2. Билсбрроу Р.Е., Хьюго Г., Обераи А.С., Злотник $X$. Статистика международной миграции: рекомендации по совершенствованию систем сбора данных. - М.: Академия, 1999. - $418 \mathrm{c}$.

3. Выршииков А. Н., Кусмариеев М.Б. Патриотическое воспитание молодежи в современном российском обществе. - Волгоград: НП ИПД Авторское перо, 2006. - 172 с.

4. Денисенко М.Б. Эмиграция из России в страны дальнего зарубежья // ДемоскопWeekly. - №513-514. - 4-17 июня 2012 г.

5. Духовность и социальное служение. Ценностный мир российской молодежи. Коллективная монография: в 3 т. Т. 1. / Под общ. ред. Т. К. Ростовской, А. М. Егорычева. - М.: Перспектива, 2018. - 296 с.

6. Зубок Ю.А., Ростовская Т.К., Смакотина Н.Л. Молодежь и молодежная политика в современном российском обществе. М.: ИТД «ПЕРСПЕКТИВА», 2016. - $166 \mathrm{c}$.

7. Ильинский И.М., Луков Вал. А. Государственная молодежная политика в России: философия преемственности и смены поколений // Знание. Понимание. Умение. 2008. - №4. - С. 5-14.

8. Казаниев А. А., Боришполеи К. П. «Утечка мозгов» из России как политико-управленческая проблема // Науковедение. - 2013. C. 207-219.

9. Кон И.С. Социализация // Большая Советская Энциклопедия. 3-е изд. / гл. ред. 
А.М. Прохоров. - М.: Сов. Энциклопедия, 1976. - T. 24. - Кн. 1. - С. 221.

10. Луков Вал. А. Воспитание как ответ на вызовы глобализации // Знание. Понимание. Умение. - 2006. — №1. - С. 106-109.

11. Луков Вал. А., Луков Вл. А. Тезаурусный подход в гуманитарных науках // Знание. Понимание. Умение. - 2004. — №1. C. 93-100.

12. Меркулов П.А. Государственная молодежная политика России: исторические этапы формирования. - СПб.: Алеф-Пресс, 2013. - $515 \mathrm{c}$.

13. Милорава А.Р. Процесс политической социализации молодежи в современном российском обществе // Молодой ученый. 2017. — №13 (147). — С. 505-507.

14. Покровский В. Утечка мозгов в эпоху глобализации / Независимая газета. - Май, 2006.

15. Распоряжение Правительства РФ от 29 ноября 2014 г. №2403-p об утверждении Основ государственной молодежной политики Российской Федерации на период до 2025 года [Электронный ресурс] — Режим доступа: // http://static.government.ru/media/ files/ceFXleNUqOU.pdf. (Дата обращения: 19.07.2020 г.).

16. Полян П. М. Эмиграция: кто и когда в XX веке покидал Россию / Россия и ее регионы в XX веке: территория - расселение миграции / Под ред. О. Глезер и П. Поляна. - М.: ОГИ, 2005. - С. 493-519.

17. Постсоветские трансформации: отражение в миграциях. Под ред. Ж.А. Зайончковской и Г.С. Витковской. ЦМИ, ИНП РАН. - М.: Адамант, 2009. - 411 с.

18. Ростовская T.К. Ценностные ориентиры современной молодежи: особенности и тенденции). Монография / Т.К. Ростовская, Т.Б. Калиев. - Москва: РУСАЙНС, 2019. $228 \mathrm{c}$.

19. Ростовская Т.К., Фомина С.Н. К вопросу о системе профилактики вовлечения российской молодежи в противоправную деятельность // Человеческий капитал. 2019. - №10 (130). - С. 72-76.

20. Рязанцев С. В., Ткаченко М.Ф. Трудовая миграция из России и российская диаспора. - Ставрополь: Мир данных, 2006. - 56 с.

21. Сравнительная политология сегодня $=$ Comparative Politics Today: мировой обзор: учеб. пособие / Г. Алмонд [и др.]; сокр. пер. с англ. А.С. Богдановского, Л.А. Галкиной; науч. ред. перевода М.В. Ильин, А.Ю. Мельвиль. - М.: Аспект Пресс, 2002. - 537 с.

22. Трухин Я. Португалия - новое направление трудовой миграции россиян // Человек и труд. - 2003. - №10. - С. 20-22.

23. Тинги A. Великая миграция: Россия и россияне после падения железного занавеca. - М.: РОССПЭН, 2012. — 479 с.

24. Федеральный закон от 24.05.1999 г. №99-Ф3 (ред. от 23.07.2013 г.) «О государственной политике Российской Федерации в отношении соотечественников за рубежом» [Электронный ресурс] - Режим доступа: http://www.kremlin.ru/acts/bank/13875. (Дата обращения: 19.07.2020 г.).

25. Федотова В.Г. «Хорошее общество»: Социальное конструирование приемлемого для жизни общества. - М.: Прогресс-Традиция, 2005. - $544 \mathrm{c}$.

\section{References}

1. Kolsto $P$. The new Russian diaspora - An identity of its own? Possible identity trajectories for Russians in the former Soviet republic // Ethnic and Racial Studies. — 1996. — №19(3). Pp. 609-639.

2. Bilsbrrou R.E., H'jugo G., Oberai A.S., Zlotnik H. Statistika mezhdunarodnoj migracii: rekomendacii po sovershenstvovaniju sistem sbora dannyh [International migration statistics: recommendations for improving data collection systems]. - Moscow: Akademija, 1999. — 418 p.

3. Vyrshhikov A.N., Kusmarcev M.B. Patrioticheskoe vospitanie molodezhi v sovremennom rossijskom obshhestve [Patriotic education of young people in modern Russian society]. - Volgograd: NP IPD Avtorskoe pero, 2006. - $172 \mathrm{p}$.

4. Denisenko M.B. Jemigracija iz Rossii v strany dal'nego zarubezh'ja [Emigration from Russia to foreign countries] // DemoskopWeekly. - №513-514. - June 4-17, 2012.

5. Duhovnost' i social'noe sluzhenie. Cennostnyj mir rossijskoj molodezhi. Kollektivnaja monografija: v 3 t. T. 1 [Spirituality and social service. The value world of Russian youth. A collective monograph: in 3 vols. Vol. 1]. / In T.K. Rostovskaya, A. M. Egorychev (ed.). Moscow: Perspektiva, 2018. - 296 p.

6. Zubok Ju. A., Rostovskaja T.K., Smakotina N.L. Molodezh' i molodezhnaja politika $\mathrm{v}$ 
sovremennom rossijskom obshhestve [Youth and youth policy in modern Russian society]. - Moscow: ITD «PERSPEKTIVA», 2016. - 166 p.

7. Il'inskij I. M., Lukov Val. A. Gosudarstvennaja molodezhnaja politika $v$ Rossii: filosofija preemstvennosti i smeny pokolenij [State youth policy in Russia: the philosophy of succession and change of generations] // Znanie. Ponimanie. Umenie [Knowledge. Understanding. Skill]. - 2008. - №4. - Pp. 5-14.

8. Kazancev A. A., Borishpolec K. P. «Utechka mozgov» iz Rossii kak politiko-upravlencheskaja problema [The «brain drain» from Russia as a political and managerial problem] // Naukovedenie [Science of Science]. — 2013. Pp. 207-219.

9. Kon I.S. Socializacija [Socialization] // Bol'shaja Sovetskaja Jenciklopedija. 3-e izd. [The Great Soviet Encyclopedia. 3-e Izd.] / In A. M. Prohorov (ed.). - Moscow: Sov. Jenciklopedija, 1976. - Vol. 24. - Issue 1. P. 221.

10. Lukov Val. A. Vospitanie kak otvet na vyzovy globalizacii [Education as a response to the challenges of globalization] // Znanie. Ponimanie. Umenie [Knowledge. Understanding. Skill]. - 2006. — №1. - Pp. 106-109.

11. Lukov Val. A., Lukov Vl. A. Tezaurusnyj podhod $\mathrm{v}$ gumanitarnyh naukah [Thesaurus approach in the Humanities] // Znanie. Ponimanie. Umenie [Knowledge. Understanding. Skill]. 2004. - №1. - Pp. 93-100.

12. Merkulov P.A. Gosudarstvennaja molodezhnaja politika Rossii: istoricheskie jetapy formirovanija [State youth policy of Russia: historical stages of formation]. - Saint-Petersburg: Alef-Press, 2013. - 515 p.

13. Milorava A.R. Process politicheskoj socializacii molodezhi v sovremennom rossijskom obshhestve [The process of political socialization of youth in modern Russian society] // Molodoj uchenyj [Young scientist]. — 2017. №13 (147). - Pp. 505-507.

14. Pokrovskij $V$. Utechka mozgov v jepohu globalizacii [Brain drain in the era of globalization] / Nezavisimaja gazeta. - May, 2006.

15. Rasporjazhenie Pravitel'stva RF ot 29 nojabrja 2014 g. №2403-r ob utverzhdenii Osnov gosudarstvennoj molodezhnoj politiki Rossijskoj Federacii na period do 2025 goda [Decree of the Government of the Russian Federation of November 29, 2014 №2403-R on approving the
Basics of the state youth policy of the Russian Federation for the period up to 2025] [Jelektronnyj resurs] — URL: // http://static.government. ru/media/files/ceFXleNUqOU.pdf. (Date accessed: 19.07.2020).

16. Poljan P.M. Jemigracija: kto i kogda v XX veke pokidal Rossiju / Rossija i ee regiony $\mathrm{v}$ XX veke: territorija - rasselenie - migracii [Emigration: who and when left Russia in the XX century / Russia and its regions in the XX century: territory-settlement-migration]/ In O. Glezer and P. Poljan (ed.). - Moscow: OGI, 2005. - Pp. 493-519.

17. Postsovetskie transformacii: otrazhenie $\mathrm{v}$ migracijah [Post-Soviet transformations: reflection in migrations]. In $\mathrm{Zh}$. A. Zajonchkovskaya and G.S. Vitkovskaya (ed.). CMI, INP RAN. - Moscow: Adamant, 2009. - 411 p.

18. Rostovskaja T.K. Cennostnye orientiry sovremennoj molodezhi: osobennosti i tendencii): monografija [Value orientations of modern youth: features and trends. Monograph] / T.K. Rostovskaja, T.B. Kaliev. - Moscow: RUSAJNS, 2019. - 228 p.

19. Rostovskaja T.K., Fomina S. N. K voprosu o sisteme profilaktiki vovlechenija rossijskoj molodezhi v protivopravnuju dejatel'nost' [On the issue of prevention of involvement of Russian youth in illegal activities] // Chelovecheskij kapital [Human capital]. — 2019. — №10(130). Pp. 72-76.

20. Rjazancev S. V., Tkachenko M.F. Trudovaja migracija iz Rossii i rossijskaja diaspora [Labor migration from Russia and the Russian Diaspora]. — Stavropol': Mir dannyh, 2006. — 56 p.

21. Sravnitel'naja politologija segodnja $=$ Comparative Politics Today: mirovoj obzor: ucheb. posobie [Comparative political science today = Comparative Politics Today: world review: studies. Manual] / G. Almond [ets.]; In M. V. Ilyin, A. Yu. Melville (ed.). - Moscow: Aspekt Press, 2002. - 537 p.

22. Truhin Ja. Portugalija - novoe napravlenie trudovoj migracii rossijan [Portugal - a new direction of Russian labor migration] // Chelovek i trud [Man and labor]. - 2003. №10. - Pp. 20-22.

23. Tingi $A$. Velikaja migracija: Rossija i rossijane posle padenija zheleznogo zanavesa [The great migration: Russia and Russians after the fall of the iron curtain]. - Moscow: ROSSPJeN, 2012. - $479 \mathrm{p}$. 
24. Federal'nyj zakon ot 24.05.1999 g. №99-FZ (red. ot 23.07.2013 g.) «O gosudarstvennoj politike Rossijskoj Federacii v otnoshenii sootechestvennikov za rubezhom» [Federal law №99-FZ of 24.05.1999 (ed. from 23.07.2013) «On the state policy of the Russian Federation in relation to compatriots abroad»] [Jelektron- nyj resurs] — URL: http://www.kremlin.ru/acts/ bank/13875. (Date accessed: 19.07.2020).

25. Fedotova V.G. «Horoshee obshhestvo»: Social'noe konstruirovanie priemlemogo dlja zhizni obshhestva [«Good society»: Social construction of an acceptable society]. - Moscow: Progress-Tradicija, 2005. - 544 p.
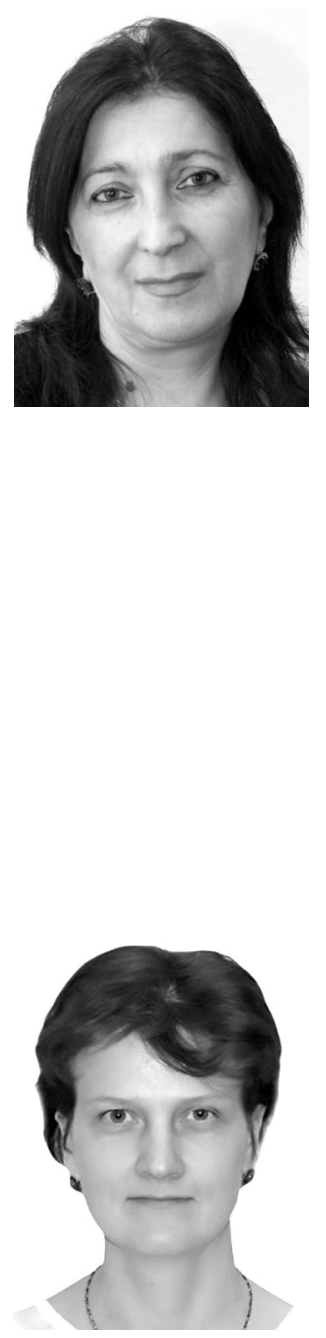

Ростовская Тамара Керимовна - доктор социологических наук, профессор, заместитель директора Института демографических исследований Федерального научно-исследовательского социологического центра Российской академии наук.

Rostovskaya Tamara Kerimovna - Doctor of Sociological Sciences, Professor, Deputy Director, Institute of Demographic Research of the Federal Research Sociological Center, Russian Academy of Sciences.

119333, г. Москва, ул. Фотиевой, 6, стр. 1 6 Fotievoj st., bld. 1, 119333, Moscow, Russia

E-mail: rostovskaya.tamara@mail.ru

Гневашева Вера Анатольевна - доктор экономических наук, руководитель отдела воспроизводства трудовых ресурсов и занятости населения Института демографических исследований Федерального научно-исследовательского социологического центра Российской академии наук.

Gnevasheva Vera Anatolyevna - Doctor of Economic Sciences, Head of the Department of Reproduction of Labor Resources and Employment, Institute of Demographic Research of the Federal Research Sociological Center of the Russian Academy of Sciences.

119333, г. Москва, ул. Фотиевой, 6, стр. 1

6 Fotievoj st., bld. 1, 119333, Moscow, Russia

E-mail: vera_cos@rambler.ru 


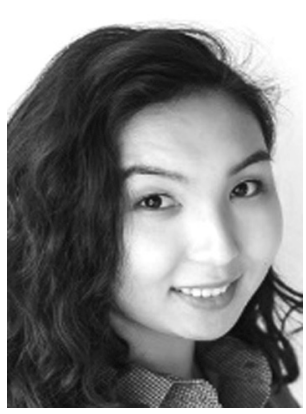

Очирова Галина Николаевна - младший научный сотрудник Института демографических исследований Федерального научно-исследовательского социологического центра Российской академии наук.

Ochirova Galina Nickolaevna - Junior Researcher, Institute of Demographic Research of the Federal Research Sociological Center of the Russian Academy of Sciences.

119333, г. Москва, ул. Фотиевой, 6, стр. 1

6 Fotievoj st., bld. 1, 119333, Moscow, Russia

E-mail: galinaochirova93@gmail.com 